\title{
Acute oral toxicity of Insampaedok-san, a traditional herbal formula, in rats and its protective effects against ovalbumin-induced asthma via anti-inflammatory and antioxidant properties
}

\author{
Yeji Kim, Mee-Young Lee, Ohn-Soon Kim, Woo-Young Jeon and Hyeun-Kyoo Shin ${ }^{*}$
}

\begin{abstract}
Background: Insampaedok-san (ren-shen-bai-du-san in Chinese) is a traditional herbal formula widely used for the treatment of respiratory diseases in Korea and China. In this study, we investigated the acute oral toxicity of an Insampaedok-san water extract (ISSE) in rats and the antiasthmatic effects of ISSE and its mechanism in a model of asthma induced by ovalbumin (OVA) in mice.

Methods: In a safety study, ISSE was administrated orally to rats of both sexes at single doses of 0 and $5000 \mathrm{mg} / \mathrm{kg}$. We observed body weight changes, mortality, clinical signs, and gross pathological findings. In vitro antioxidant activity of ISSE was measured using 2,2-diphenyl-2-picrylhydrazyl and 2,2-azino-bis(3-ethylbenzothiazoline-6-sulfonic acid radical scavenging methods. A model of asthma was established in mice by sensitization and challenge with OVA. We assessed the levels of type 2 T-helper cytokines, chemokines, and immunoglobulin levels, using enzyme-linked immunosorbent assays, and superoxide dismutase (SOD) activity using a kit.

Results: No adverse effects were observed in the acute ISSE toxicity study. ISSE showed potent free radical scavenging activity and inhibited the recruitment of inflammatory cells into the lung and mucus hypersecretion in OVA-challenged mice. ISSE significantly decreased levels of interleukin (IL)-4, IL-5, eotaxin, and OVA-specific immunoglobulin (Ig)E, and increased SOD activity.

Conclusions: These results indicate that ISSE is safe for human consumption and its antiasthmatic effect is associated with the ability of ISSE to attenuate inflammation and oxidative stress.
\end{abstract}

Keywords: Insampaedok-san, Safety, Cytokine, Free radical scavenging, Asthma

\section{Background}

Asthma is a chronic inflammatory disease of the airways. The pathological changes in asthma include airway obstruction, mucus hyperproduction, and increased infiltration of inflammatory cells, including eosinophils, mast cells, and lymphocytes [1]. Type 2 T-helper (Th2) cells activated by allergens play a pivotal role in the development of asthma. Activated Th2 cells produce various cytokines, including interleukin (IL)-4, IL-5, and IL-13, which induce

\footnotetext{
* Correspondence: cozy37@gmail.com

Herbal Medicine Formulation Research Group, Korea Institute of Oriental Medicine, 483 Expo-ro, Yusung-gu, Daejeon 305-811, Republic of Korea
}

activation and recruitment of inflammatory cells, and overproduction of mucus, during the inflammatory process in asthma. Th2 cytokines can also lead to the production of allergen-specific immunoglobulin (Ig)E antibodies by $\mathrm{B}$ cells [2,3]. Inflammation in the airways induces oxidative damage. Activated immune cells, such as macrophages, neutrophils, and lymphocytes, release reactive oxygen species (ROS) [4]. Airway cells and tissues are also exposed to exogenous ROS stress from air pollutants and cigarette smoke [5]. Increased oxidative stress exacerbates inflammation by inducing proinflammatory mediators and contributes to the development of asthma [6]. 
Insampaedok-san (ISS; ren-shen-bai-du-san in Chinese) is a traditional herbal formula widely used for the treatment of common cold-related symptoms in Korea and China [7]. There are several case studies demonstrating the efficacy of ISS for respiratory diseases, such as the common cold and asthma [8-11]. It has been reported that the administration of this herbal medicine effectively attenuates symptoms of asthma and reduces the rate of relapse $[10,11]$. Our previous in vitro study revealed that Insampaedok-san has anti-inflammatory, anti-allergic, and anti-obesity effects [12]. Therefore, in the present study, we performed an acute oral toxicity study of ISS in rats to establish a safety profile for ISS. In addition, we examined the antioxidant activity of ISS and its antiasthmatic effects by using a mouse model of asthma induced by ovalbumin (OVA) in vivo to investigate the mechanism underlying the effectiveness of ISS in the treatment of asthma.

\section{Methods}

Preparation of the Insampaedok-san water extract (ISSE)

ISSE was prepared in our laboratory from a mixture of chopped crude herbs (Table 1). Before performing the study, the identity of each crude herb was confirmed by Professor Je-Hyun Lee of Dongguk University (Gyeongju, Korea). ISSE was extracted in distilled water at $100^{\circ} \mathrm{C}$ for $2 \mathrm{~h}$. The solution was evaporated to dryness and freezedried (extraction yield: $20.89 \%$ ).

Table 1 Composition of ISSE

\begin{tabular}{|c|c|c|c|c|}
\hline Scientific name & $\begin{array}{l}\text { Part of } \\
\text { use }\end{array}$ & $\begin{array}{l}\text { Amount } \\
\text { (g) }\end{array}$ & $\begin{array}{l}\text { Company of } \\
\text { purchase }\end{array}$ & Source \\
\hline Panax ginseng & Radix & 3.75 & Omniherb & $\begin{array}{l}\text { Geumsan, } \\
\text { Korea }\end{array}$ \\
\hline Bupleurum falcatum & Radix & 3.75 & HMAX & China \\
\hline Angelica decursiva & Radix & 3.75 & HMAX & China \\
\hline Ostericum koreanum & Radix & 3.75 & HMAX & China \\
\hline Aralia continentalis & Radix & 3.75 & Omniherb & $\begin{array}{c}\text { Yeongcheon, } \\
\text { Korea }\end{array}$ \\
\hline Citrus aurantium & Fructus & 3.75 & HMAX & China \\
\hline $\begin{array}{l}\text { Platycodon } \\
\text { grandiflorum }\end{array}$ & Radix & 3.75 & Omniherb & $\begin{array}{c}\text { Yeongcheon, } \\
\text { Korea }\end{array}$ \\
\hline Cnidium officinale & Rhizoma & 3.75 & Omniherb & $\begin{array}{c}\text { Yeongcheon, } \\
\text { Korea }\end{array}$ \\
\hline Poria cocos & Hoelen & 3.75 & HMAX & China \\
\hline Glycyrrhiza uralensis & Radix & 3.75 & HMAX & China \\
\hline Mentha arvensis & Herba & 3.75 & Omniherb & $\begin{array}{c}\text { Yeongcheon, } \\
\text { Korea }\end{array}$ \\
\hline Zingiber officinale & Rhizoma & 3.75 & Omniherb & $\begin{array}{c}\text { Yeongcheon, } \\
\text { Korea }\end{array}$ \\
\hline Total amount & & 45.00 & & \\
\hline
\end{tabular}

\section{Animals for acute oral toxicity study}

Twenty Sprague Dawley (SD) rats (5 weeks) of each sex were obtained from the Orient Bio Co. (Seoul, Korea). They were acclimated to laboratory conditions for 5 days and housed three per cage in an animal experiment room where the temperature was set at $23 \pm 3^{\circ} \mathrm{C}$, humidity at $50 \pm 10 \%$, ventilation frequency at 10-20 times per hour. They had free access to sterilized tap water and commercial rodent chow (PMI Nutrition International, USA). This study was performed at the Korea Institute of Toxicology (KIT) (Daejeon, Republic of Korea) and conducted according to guidance from the Institutional Animal Care and Use Committee at the KRICT (accredited by AAALAC International, 1998) under the GLP Regulations for Nonclinical Laboratory Studies.

In a previous experiment for dose selection, we conducted an acute toxicity study with three dose levels of 1250,2500 , and $5000 \mathrm{mg} / \mathrm{kg}$. We found no signs of toxicity at these three dose levels. Based on these findings, we determined $5000 \mathrm{mg} / \mathrm{kg}$ as an experimental dose for the 15-day acute toxicity study. Both the ISSE group and the vehicle-only control group consisted of five rats of each sex. ISSE and distilled water (vehicle control group) were administered to rats in the treatment and control group, respectively, via oral gavage once a day and were observed for 15 days.

The general symptoms, signs of toxicity and mortality were observed over $6 \mathrm{~h}$ after the initiation of administration, and once a day for 15 days. The body weight of each rat was measured before the treatment and 2, 4, 8, and 15 days after treatment. At the end of the study (day $15)$, all rats were sacrificed by bleeding from the abdominal aorta under $\mathrm{CO}_{2}$ anesthesia and we performed gross observation.

\section{2,2'-azino-bis(3-ethylbenzothiazoline-6-sulfonic acid) diammonium salt (ABTS) radical scavenging activity}

The ABTS radical scavenging activity of the extracts was determined using a method described by Re et al. [13], with slight modifications. Briefly, ABTS radical cation was produced by reacting $7 \mathrm{mM}$ ABTS solution with $2.45 \mathrm{mM}$ potassium persulfate stored in the dark at room temperature for $16 \mathrm{~h}$. Prior to the assay, the solution was diluted with phosphate buffered saline (PBS, $\mathrm{pH} 7.4$ ) to an absorbance of 0.7 at $734 \mathrm{~nm}$. Then, ABTS ${ }^{+}$solution was added to a 96-well plate containing samples. After $5 \mathrm{~min}$ of incubation, the absorbance was immediately measured at $734 \mathrm{~nm}$ using a microplate reader (Benchmark Plus, Bio-Rad, USA). The extent of decolorization was calculated as the percentage reduction of absorbance. The scavenging capability of test compounds was calculated using the following equation: 
ABTS radical scavenging activity $=\left(1-\mathrm{A}_{\text {sample }} / \mathrm{A}_{\text {control }}\right) \times 100$,

where $\mathrm{A}_{\text {control }}$ was the absorbance of the negative control, and $\mathrm{A}_{\text {sample }}$ was the absorbance of the standard antioxidant or extract. $\mathrm{RC}_{50}$ values (the concentration required for $50 \%$ reduction of ABTS radical) were calculated from the absorbance diminished by $50 \%$.

\section{2,2'-diphenyl-2-picrylhydrazyl radical (DPPH) scavenging activity}

Radical scavenging activity of extracts was determined using DPPH as a free radical using the method described by Moreno et al. [14], with some modifications. Briefly, $100 \mu \mathrm{L}$ of various concentrations of sample was added to $100 \mu \mathrm{L}$ of DPPH solution $(0.15 \mathrm{mM}$ in ethanol) in a 96-well plate. After $30 \mathrm{~min}$ incubation in the dark at room temperature, the absorbance was measured at $517 \mathrm{~nm}$. Activity of scavenging (\%) was calculated using the above formula.

\section{Model of asthma induced by OVA and treatment}

Seven-week-old female BALB/c mice, obtained from Orient Co. (Seoul, Korea), were used after 1 week of acclimation. All experimental procedures were conducted in accordance with the NIH Guidelines for the Care and Use of Laboratory Animals and were approved by Korea Institute of Oriental Medicine Institutional Animal Care and Use Committee. The animals were cared for in accordance with the dictates of the National Animal Welfare Law of Korea. Mice were divided into five groups, including a normal control group, an asthma model group, a positive control group treated with montelukast (30 mg/kg, Sigma, St. Louis, MO), and the ISSE-treated group (100 and $200 \mathrm{mg} / \mathrm{kg}$ ). Briefly, mice in the asthma model group were sensitized with an intraperitoneal injection of $20 \mu \mathrm{g}$ OVA and $2 \mathrm{mg}$ aluminum hydroxide in $200 \mu \mathrm{L}$ PBS buffer (pH 7.4) on days 0 and 14. On days 21, 22 , and 23 after initial sensitization, mice were challenged with OVA (1\%, w/v, in PBS) for $1 \mathrm{~h}$ using an ultrasonic nebulizer (NE-U12; Omron Co., Tokyo, Japan). Mice in the positive control and ISSE groups were treated orally with montelukast and ISSE (100 mg/ $\mathrm{kg}$ and $200 \mathrm{mg} / \mathrm{kg}$ ), respectively, once daily on days $18-23$. Mice in the normal control and asthma model groups were given PBS. Animals were sacrificed by intraperitoneal injection of pentobarbital (50 mg/kg, Hanlim Pharm., Seoul, Korea) 48 h after the final challenge.

\section{Inflammatory cell counts in bronchoalveolar lavage fluid (BALF)}

Mice were sacrificed with an overdose of pentobarbital $48 \mathrm{~h}$ after the final challenge. BALF was collected by washing lungs with ice-cold PBS (total volume of $1.8 \mathrm{~mL}$ ) via tracheal cannulation. BALF was centrifuged and cell pellets were resuspended in $0.5 \mathrm{~mL} \mathrm{PBS}$, and cells in $100 \mu \mathrm{L}$ of each solution spun onto a slide using a cytospin device (Hanil Science Industrial, Seoul, Korea). After the slides were dried, cells were stained using Diff-Quik Staining reagent (B4132-1A; Dade Behring, Deerfield, IL), according to the manufacturer's instructions.

\section{Measurement of cytokines and chemokine levels in BALF}

The concentrations of IL-4, IL-5, and eotaxin in BALF of mice were measured using enzyme-linked immunosorbent assay (ELISA) kits following the manufacturer's instructions (BioSource International, Camarillo, CA, USA).

\section{Detection of OVA-specific immunoglobulin (Ig)E levels in BALF and serum}

Serum was collected and stored at $-70^{\circ} \mathrm{C}$ after centrifugation $(200 \mathrm{~g}, 10 \mathrm{~min})$. Total and OVA-specific IgE levels were measured by ELISA. Microtiter plates were coated overnight with $10 \mu \mathrm{g} / \mathrm{mL}$ OVA in PBS-Tween 20. After washing and blocking the plate, samples were incubated for $2 \mathrm{~h}$, and then HRP-conjugated goat anti-mouse IgE was added. After washing, $200 \mu \mathrm{L}$ of o-phenylenediamine dihydrochloride (Sigma, St. Louis, MO) was added to each well.
$\mathbf{A}$

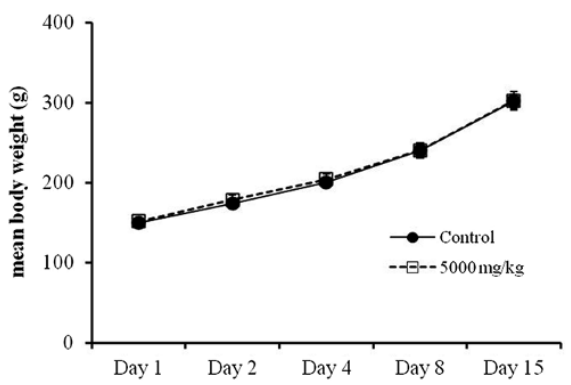

B

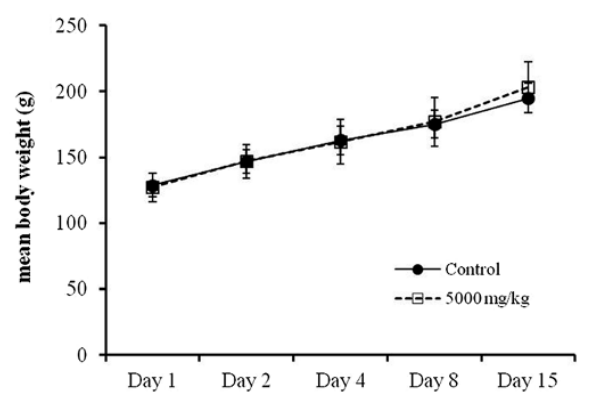

Figure 1 Changes in the body weight of rats treated with ISSE for 15 days. Time course of mean body weight after oral administration of ISSE to male (A) and female (B) rats. 
Table 2 Scavenging effects of ISSE on ABTS +

\begin{tabular}{llll}
\hline Herbal formula & $\begin{array}{l}\text { Concentration } \\
(\boldsymbol{\mu} \mathbf{g} / \mathbf{m L})\end{array}$ & $\begin{array}{l}\text { Scavenging effect } \\
(\%)\end{array}$ & $\begin{array}{l}\mathbf{R C} \mathbf{5}_{\mathbf{5 0}}^{1} \\
(\boldsymbol{\mu g} / \mathbf{m L})\end{array}$ \\
\hline ISSE $^{2}$ & 25 & $18.20 \pm 1.33$ & $121.65 \pm 0.88$ \\
& 50 & $29.48 \pm 0.86$ & \\
& 100 & $49.98 \pm 0.61$ & \\
& 200 & $71.85 \pm 0.06$ & $3.22 \pm 0.06$ \\
$\mathrm{AA}^{3}$ & 1.25 & $21.15 \pm 0.19$ & \\
& 2.5 & $40.61 \pm 1.44$ & \\
& 5 & $75.86 \pm 1.06$ & \\
\hline
\end{tabular}

${ }^{1}$ Concentration required for $50 \%$ reduction of $\mathrm{ABTS}^{+}$at 5 -min reaction ${ }^{2}$ Insampaedok-san and ${ }^{3}$ ascorbic acid.

Each value is the mean \pm S.E.M. of triplicate determinations.

After incubation for $10 \mathrm{~min}$ in the dark, absorbance was measured at $450 \mathrm{~nm}$ using a microplate ELISA reader.

\section{Measurement of superoxide dismutase (SOD) level in lung tissue}

The homogenates of lung tissues were centrifuged at $12,000 \mathrm{~g}$ for $20 \mathrm{~min}$ to collect supernatants for determination of SOD activity. SOD activity was assayed using a kit according to the manufacturer's instructions (Cayman, Michigan, CA). SOD activity was determined with a modified method using a NADH-phenazine methosulfatenitroblue tetrazolium formazan inhibition reaction, which was measured spectrophotometrically at $560 \mathrm{~nm}$.

\section{Histopathology}

After BALF were obtained, lung tissue was removed, fixed with $10 \%(\mathrm{v} / \mathrm{v})$ neutral buffered formalin. Tissues were embedded in paraffin, sectioned at $4 \mu \mathrm{m}$ thickness, and stained with hematoxylin and eosin (H\&E) (Sigma, St. Louis, MO) and periodic acid-Schiff (PAS) solution (IMEB, San Marcos, CA) to assess inflammation and
Table 3 Scavenging effects of ISSE on DPPH

\begin{tabular}{llll}
\hline Herbal formula & $\begin{array}{l}\text { Concentration } \\
(\boldsymbol{\mu} \mathbf{g} / \mathrm{mL})\end{array}$ & $\begin{array}{l}\text { Scavenging effect } \\
(\%)\end{array}$ & $\begin{array}{l}\mathrm{RC}_{50}^{1} \\
(\boldsymbol{\mu} \mathbf{g} / \mathbf{m L})\end{array}$ \\
\hline $\mathrm{ISSE}^{2}$ & 50 & $1.55 \pm 0.53$ & $346.93 \pm 3.28$ \\
& 100 & $8.58 \pm 0.59$ & \\
& 200 & $26.48 \pm 0.61$ & \\
& 400 & $58.58 \pm 0.52$ & \\
$\mathrm{AA}^{3}$ & 2.5 & $9.56 \pm 1.26$ & $10.43 \pm 0.23$ \\
& 5 & $24.27 \pm 1.40$ & \\
& 10 & $58.79 \pm 0.70$ & \\
\hline
\end{tabular}

${ }^{1}$ Concentration required for $50 \%$ reduction of DPPH at 30 -min reaction. ${ }^{2}$ Insampaedok-san and ${ }^{3}$ ascorbic acid.

Each value is the mean \pm S.E.M. of triplicate determinations.

mucus production, respectively. Tissue sections were examined microscopically.

\section{Statistical analysis}

Data are expressed as means \pm S.E.M. Statistical comparisons were made using a one-way analysis of variance (ANOVA). $P<0.05$ was considered statistically significant.

\section{Results}

\section{Acute oral toxicity study of ISSE in rats}

No rats died during the 15-day acute toxicity study. There was no significant difference in body weight of either male or female rats between the ISSE-treated group and the control group during the 15-day observation period (Figure 1). No abnormal signs regarding general appearance, behavior, or nervous system were observed in rats from the ISSE-treated group compared with the control group rats. Moreover, we did not detect any clinical signs of adverse effects or any abnormal gross autopsy findings induced by ISSE treatment for 15 days.

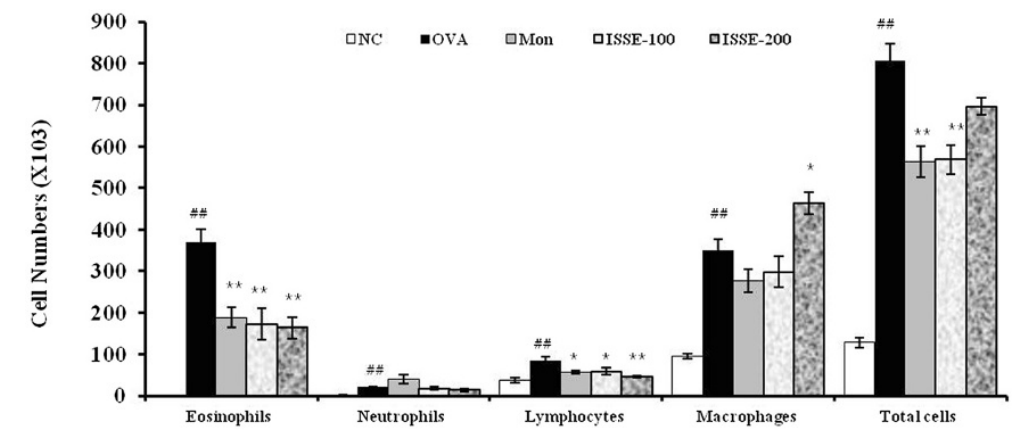

Figure 2 Effects of ISSE on the recruitment of inflammatory cells in bronchoalveolar lavage fluid (BALF) of mice. Mouse BALF waS collected $48 \mathrm{~h}$ after final OVA challenge. Cell numbers within at least five squares of a hemocytometer were counted using a light microscope. Dead cells were excluded using trypan blue staining. NC, negative control (PBS only); OVA, OVA-sensitized/challenged mice; Mon, montelukast (30 mg/kg) + OVA-sensitized/challenged mice; ISSE-100, ISEE (100 mg/kg) + OVA-sensitized/challenged mice; ISSE-200, ISEE (200 mg/kg) + OVAsensitized/challenged mice. Significantly different from NC, ${ }^{\#} P<0.05$, ${ }^{\# \#} P<0.01$; significantly different from OVA, ${ }^{*} P<0.05,{ }^{* *} P<0.01$. 
Antioxidant activity of ISSE in vitro

To evaluate the antioxidant activity of ISSE, we tested its scavenging activities on ABTS and DPPH radicals. ABTS radical scavenging activities of ISSE are presented in
Table 2 as a percentage of ABTS radical scavenging activity. ISSE showed the radical scavenging activity in a dose-dependent manner. The scavenging activities of ISSE were $18.19,29.48,49.98$, and $71.85 \%$ at $25,50,100$,
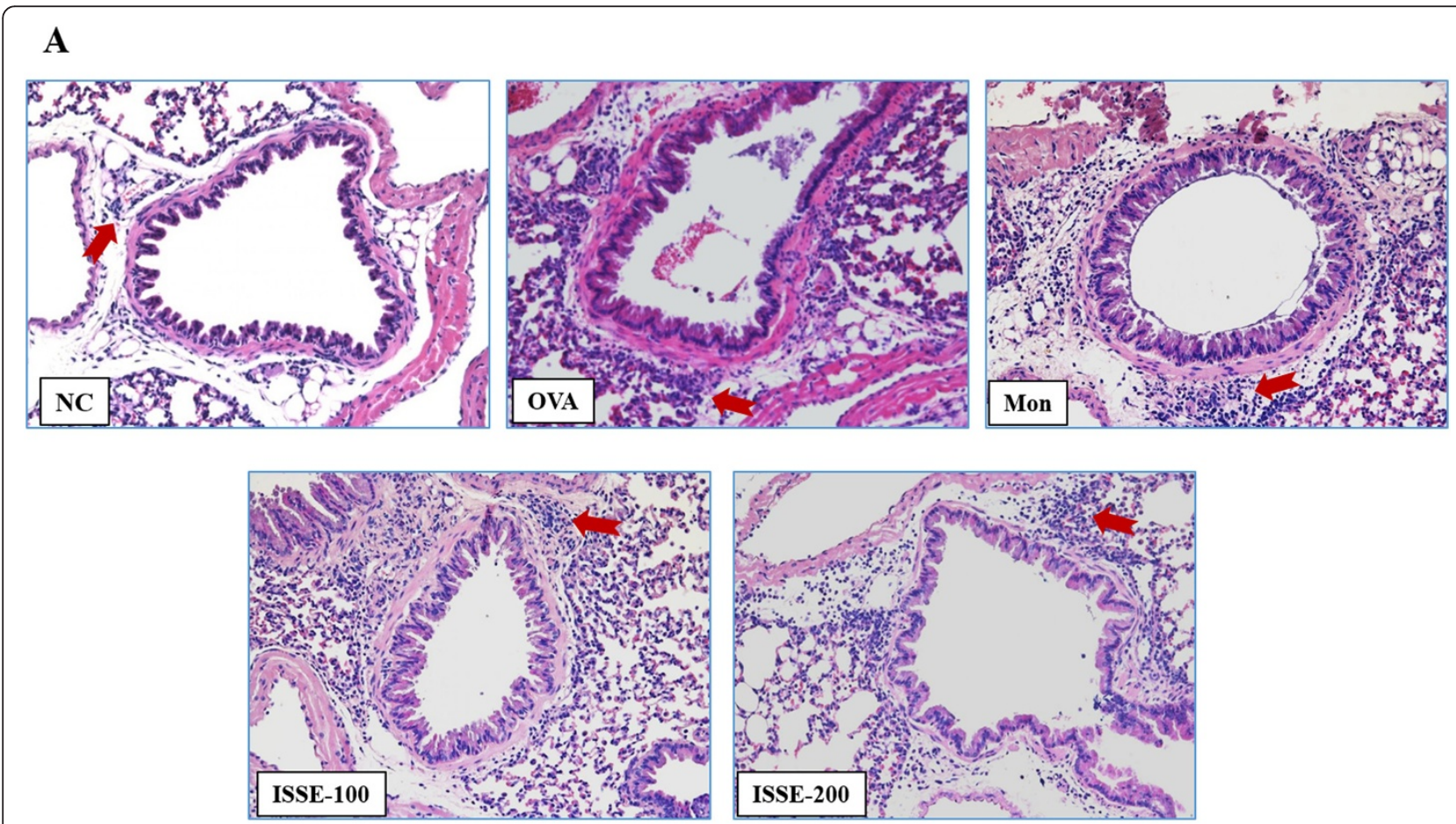

B
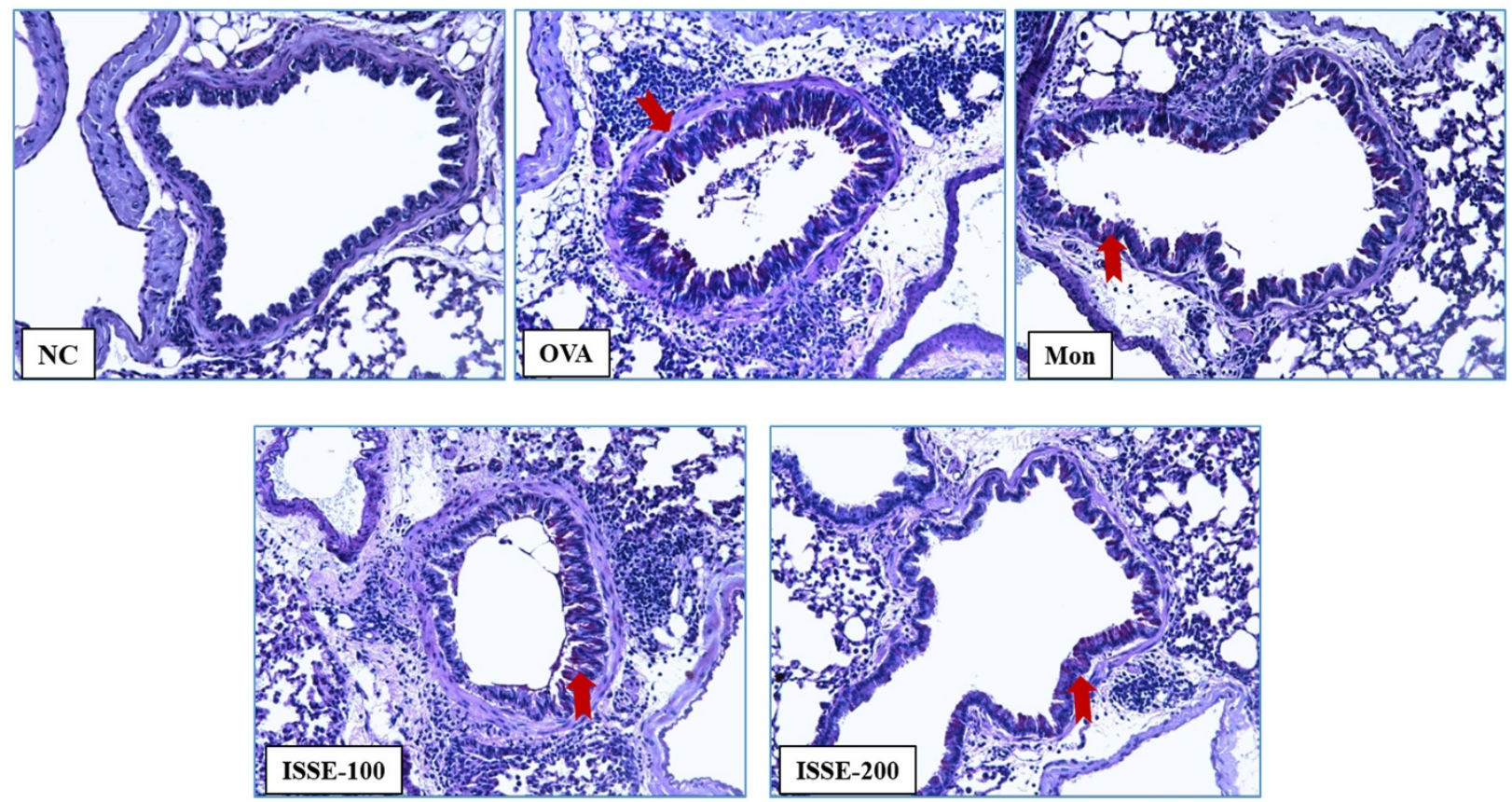

Figure 3 Effects of ISSE on the recruitment of inflammatory cells to lung tissue (A) and mucus production (B). Histological examination of lung tissues was performed $48 \mathrm{~h}$ after the final OVA challenge. Lung tissues were stained with H\&E (A) and PAS (B). NC, negative control (PBS only); OVA, OVA-sensitized/challenged mice; Mon, montelukast (30 mg/kg) + OVA-sensitized/challenged mice; ISSE-100, ISEE (100 mg/kg) + OVAsensitized/challenged mice; ISSE-200, ISEE (200 mg/kg) + OVA-sensitized/challenged mice. 
and $200 \mu \mathrm{g} / \mathrm{mL}$ concentrations, respectively. The concentration required for $50 \%$ reduction $\left(\mathrm{RC}_{50}\right)$ against ABTS radicals was $121.65 \mu \mathrm{g} / \mathrm{mL}$, whereas the $\mathrm{RC}_{50}$ value of ascorbic acid, as the positive control, was $3.22 \mu \mathrm{g} / \mathrm{mL}$. The antioxidant activities obtained for ISSE using the DPPH method are shown in Table 3. Similar to the ABTS assay, ISSE reduced the DPPH radical formation in a concentration-dependent manner. The $\mathrm{RC}_{50}$ for ISSE against DPPH radicals was $346.93 \mu \mathrm{g} / \mathrm{mL}$, whereas the $\mathrm{RC}_{50}$ value of ascorbic acid was $10.43 \mu \mathrm{g} / \mathrm{mL}$.

\section{Effect of ISSE on cell numbers in BALF}

Inflammatory cells infiltrate the airways and secrete various cytokines and mediators that aggravate airway
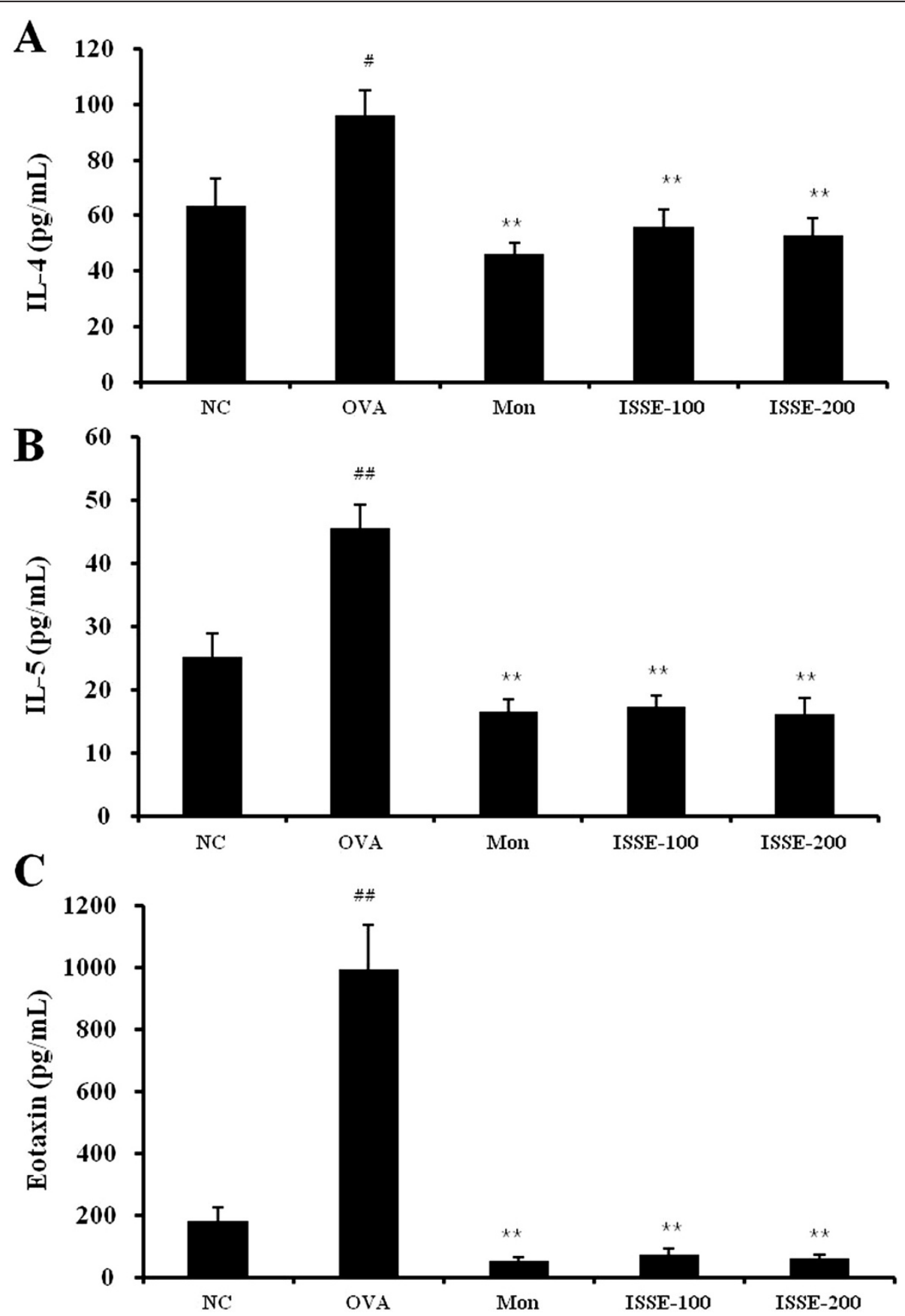

Figure 4 Effects of ISSE on IL-4, IL-5, and eotaxin levels in BALF. IL-4 (A), IL-5 (B), and eotaxin (C) levels were measured using an ELISA. NC, negative control (PBS only); OVA, OVA-sensitized/challenged mice; Mon, montelukast (30 mg/kg) + OVA-sensitized/challenged mice; ISSE-100, ISEE $(100 \mathrm{mg} / \mathrm{kg})+$ OVA-sensitized/challenged mice; ISSE-200, ISEE $(200 \mathrm{mg} / \mathrm{kg})+$ OVA-sensitized/challenged mice. Significantly different from NC, ${ }^{\#} P<0.05,{ }^{\# \#} P<0.01$; significantly different from OVA, ${ }^{*} P<0.05,{ }^{* *} P<0.01$. 
inflammation in asthma. The number of eosinophils and other inflammatory cells significantly increased in the BALF of OVA-challenged mice. By contrast, ISSE significantly suppressed recruitment of eosinophils and lymphocytes in the lungs (Figure 2).

\section{Effects of ISSE on inflammatory cell recruitment and mucus production in lung tissue}

Inflammatory cell recruitment and mucus secretion in lung tissue were observed via microscopic examination. H\&Estained lung tissue from the OVA-challenged mice showed widespread eosinophil-rich inflammation in peribronchiolar and perivascular regions, and airspaces. Administration of ISSE attenuated inflammatory cell infiltration compared with the OVA-challenged group (Figure 3A).

In lung sections stained with PAS, mucus overproduction was observed in bronchial airways of OVA-challenged mice.
The mucus staining was reduced in a dose-dependent manner in the lung tissue of mice from the ISSE-treated group (Figure 3B).

\section{Effects of ISSE on cytokines and chemokines in the BALF} of OVA-challenged mice

To investigate whether ISSE affects Th2 cytokine and chemokine secretion, we measured IL-4, IL-5, and eotaxin levels in the BALF of mice. As shown in Figure 4, OVA challenge induced a significant increase in the levels of IL-4 and IL-5 in BALF. However, the levels of IL-4 and IL-5 were decreased in ISSE-treated mice. Similar to the cytokine levels, eotaxin levels increased in the BALF of OVAchallenged mice compared with those in PBS-treated mice, while the levels of eotaxin were decreased in the ISSEtreated group.

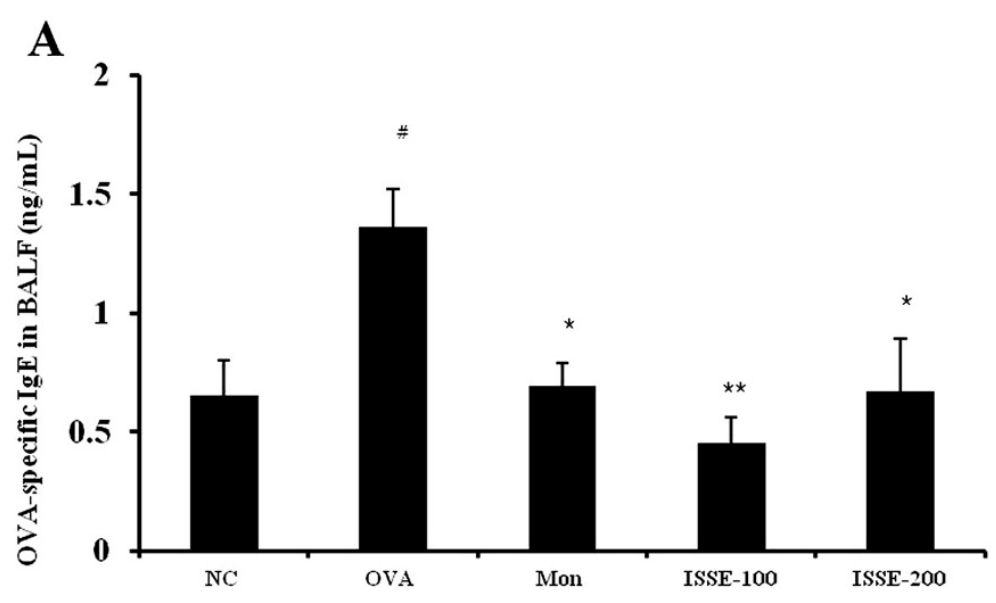

B

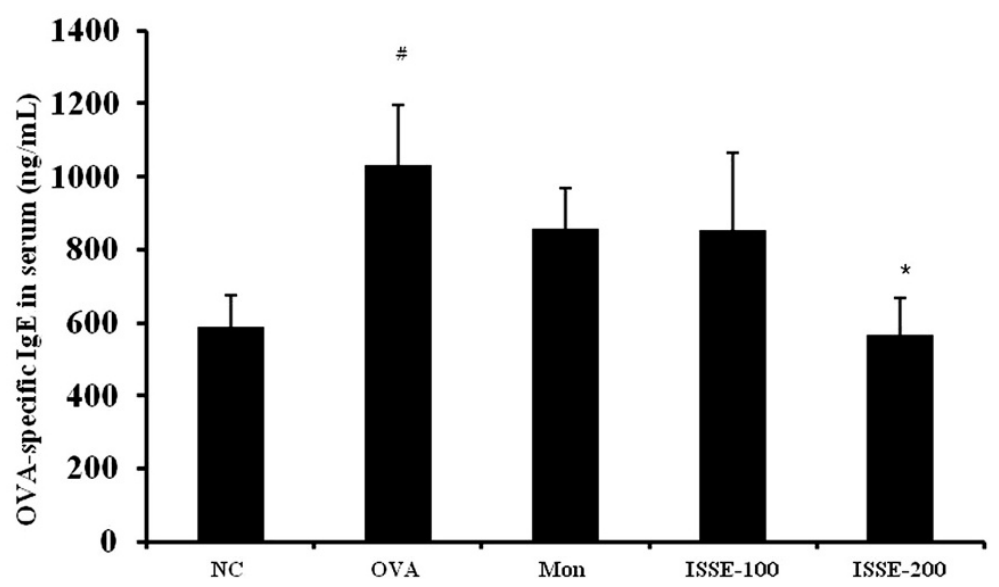

Figure 5 Effects of ISSE on the levels of OVA-specific IgE in BALF and plasma. OVA-specific lgE levels were measured using an ELISA. (A) OVA-specific lgE level in BALF (B) OVA-specific lgE level in serum. NC, negative control (PBS only); OVA, OVA-sensitized/challenged mice; Mon, montelukast (30 mg/kg) + OVA-sensitized/challenged mice; ISSE-100, ISEE (100 mg/kg) + OVA-sensitized/challenged mice; ISSE-200, ISEE (200 mg/ $\mathrm{kg})+$ OVA-sensitized/challenged mice. Significantly different from NC, ${ }^{\#} P<0.05,{ }^{\# \#} P<0.01$; significantly different from OVA, ${ }^{*} P<0.05,{ }^{* *} P<0.01$. 


\section{Effect of ISSE on OVA-specific IgE levels in the BALF and serum}

To investigate the effect of ISSE on the antibody response to allergens, the serum and BALF levels of OVAspecific IgE were measured using an ELISA. The level of OVA-specific IgE was elevated in the serum and BALF of OVA-challenged mice compared with the control group. ISSE treatment resulted in a reduction in the levels of OVA-specific IgE (Figure 5).

\section{Effect of ISSE on SOD activity and HO-1 activity in lung tissue}

To investigate the antioxidant effect of ISSE, we determined SOD activity in lung tissue. SOD activity was downregulated in mice from the asthma model group. ISSE treatment led to a marked increase in SOD activity (Figure 6).

\section{Discussion}

Traditional herbal medicine has a history of thousands of years and is still widely used in Korea and China. The evolution of traditional herbal medicine is based on observations and practical experience accumulated from millions of practitioners for thousands of years [15]. Because traditional herbal medicine does not have its own history of scientific development, there is little scientific research conducted on the safety of herbal formulas. Herbal medicines have often been provided to humans without scientifically rigorous toxicity testing. Recently, adverse effects of herbal medicines have been reported $[15,16]$. Therefore, herbal medicine toxicity studies are needed to evaluate their safety. In the present study, we performed an acute oral toxicity study of ISSE, which is used often in respiratory diseases. ISSE was given orally

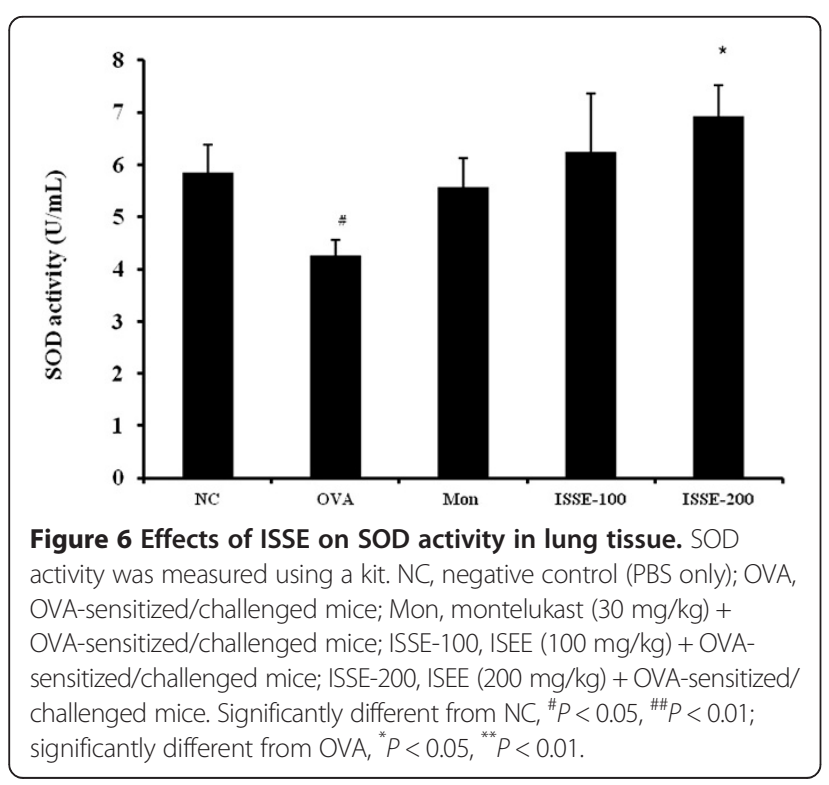

to SD rats of both sexes at dose levels of 0 and $5000 \mathrm{mg} / \mathrm{kg}$ and they were observed for 15 days. Our results showed that no deaths occurred in either the vehicle-only control group or the ISSE group. The administration of ISSE did not cause an increase or decrease in rat body weight, when compared with the control group. In addition, there were no abnormal changes in clinical signs or gross observation. Overall, ISSE did not cause any adverse effects in this study; therefore, the $\mathrm{LD}_{50}$ of ISSE was considered to be over $5000 \mathrm{mg} / \mathrm{kg}$ for oral administration in rats.

ISS has been widely used for thousands of years in China and Korea to treat patients with respiratory diseases. Clinical trials show that ISS has a beneficial effect on the treatment of asthma $[10,11]$. To evaluate its antiasthmatic effects, we performed an in vitro study on free radical scavenging activities of ISS and an in vivo study using a model of asthma induced by OVA in mice. Oxidative stress is a major feature of asthma. Many investigators have reported that increased levels of ROS in the asthmatic inflammatory process aggravate airway inflammation and damages molecules, such as proteins, DNA, and lipids $[17,18]$. It has therefore been suggested that a combination of antioxidants may have positive impact on the treatment of asthma [4]. ISS is composed of 12 herbs, Radix Ginseng, Bupleuri Radix, Angelica decursiva Radix, Osterici Radix, Aralia continentalis Radix, Aurantii Fructus Immaturus, Platycodonis Radix, Cnidii Rhizoma, Poria Sclerotium, Glycyrrhizae Radix et Rhizoma, Menthae Herba, and Zingiberis Rhizoma Crudus. Also, ISS is composed various compounds such as liquiritin, ferulic acid, naringin, hesperidin, neohesperidin, and glycyrrhizin. Several components of ISS, such as Ginseng Radix [19], Aralia continentalis Radix [20], Aurantii Fructus Immaturus [21], Platycodonis Radix [22], and Cnidii Rhizoma [23], have been reported to possess antioxidant effects. Therefore, we investigated the total free radical scavenging activity of ISSE using DPPH and ABTS assays, which involve a hydrogen atom transfer reaction and electron transfer process, respectively [24]. As shown in the results, ISSE showed both DPPH and ABTS radical scavenging activities. Shanmugasundaram et al. have reported that excessive superoxide $\left(\mathrm{O}_{2}^{-}\right)$and hydroxyl $(\mathrm{OH})$ radical and reduced free radical scavengers (vitamin $\mathrm{C}, \mathrm{E}$, glutathione) and antioxidant enzymes (SOD, glutathione peroxidase, catalase were observed in the blood of asthmatic children during asthmatic episodes and interictally [25]. Our results indicate that ISSE is a potential source of natural antioxidant, which might be helpful in lowering oxidative stress.

We investigated the antiasthmatic effects of ISSE and its possible mechanism using a model of asthma induced by OVA in mice. ISSE markedly inhibited infiltration of inflammatory cells and overproduction of mucus in lung tissue. In addition, ISSE treatment resulted in a reduction in the levels of IL-4, IL-5, and eotaxin in BALF, and 
OVA-specific IgE, both in BALF and serum. ISSE increased SOD activity in lung tissue.

The major feature of asthma is an airway inflammation, in which CD4 T-lymphocytes, eosinophils and mast cells are predominantly involved [26]. ISSE mainly decreased the numbers of lymphocytes, which regulate other effector cells in the pathogenesis of asthma [27], and eosinophils, which reflect asthmatic activity and severity of asthma $[27,28]$, in BALF. This reduction of lymphocytes may be related to the inhibitory effects of ISSE on IL-4, IL-5, and eotaxin, which induce migration and recruitment of these cells to the airways. IL-4 promotes inflammation by inducing the differentiation of Th2 cells, and expression of ICAM-1 and VCAM- 1 on endothelial cells, which increases lung cell infiltration $[29,30]$. IL-5 induces growth, maturation, activation, migration, and survival of eosinophils [31]. IL-5 mRNA levels in asthmatics has a high correlation with eosinophils, airway hyperresponsiveness, and exhaled nitric oxide levels, which reflect airway inflammation [32]. Eotaxins are potent eosinophil chemoattractants stimulated by IL-4, IL5, and IL-13 [33]. Therefore, the inhibition of eosinophil infiltration may result from less production of eotaxin and IL-5 after administration of ISSE.

Th2 cytokines are also involved in airway hyperresponsiveness and mucus production [34]. IL-4 stimulates IgE production from B lymphocytes [29]. Antigen-specific IgE binds to receptors on mast cells and sensitizes them to release mediators [35]. Activated mast cells produce diverse mediators and cytokines, which promote a hypersensitivity response characterized by contraction of bronchial smooth muscle, mucosal edema, and mucus hypersecretion [36]. Mucus hypersecretion, an important feature of asthma, is induced by eosinophils and mast-cell products [37] and goblet-cell metaplasia [34]. IL-4 and IL-5 lead to activation and infiltration of inflammatory cells. Moreover, IL-4 has the ability to differentiate airway epithelial cells into mucus-producing goblet cells [38]. In the present study, ISSE decreased OVA-specific IgE levels and mucus overproduction; this finding is consistent with its effect on Th2 cytokines.

Activated inflammatory cells can produce $\mathrm{O}_{2}{ }^{-}$and several inflammatory mediators that stimulate or promote ROS generation, which causes direct damage to tissue and cells [39] and aggravates inflammation by activation of nuclear factor kappa-B (NF-kB) [40]. SOD, an antioxidant enzyme, protects the airway from oxidant stress. However, SOD activity decreased in the oxidantrich environment of asthma, which contributes to airway remodeling and hyperreactivity of asthma [41]. We show here that ISSE increased SOD activity compared with OVA group. This further supports that the antiasthmatic effects of ISSE are at least partially mediated by its antioxidant activity.
This finding indicates that ISSE enhances SOD production, which might mediate inhibitory effects of ISSE on inflammation and produce synergistic effects for the treatment of asthma through its antioxidant activity.

\section{Conclusions}

The acute oral toxicity study in rats showed no adverse effects of ISSE up to a dose level of $5000 \mathrm{mg} / \mathrm{kg}$ in rats. The present study suggests that the beneficial effect of ISSE on asthma is associated with its antioxidant and anti-inflammatory activities. ISSE has free radical scavenging activity in vitro, and enhances SOD activity in lung tissue in a model of asthma in mice. ISSE suppresses inflammation induced by asthma by reducing infiltration of inflammatory cells, production of Th2 cytokines, chemokine, and antigen-specific IgE, and attenuating mucus hypersecretion. This study provides information regarding the safety and mechanism of antiasthmatic effects of ISSE. However, further research on constituents compounds's activity and chronic toxicity are required.

\section{Competing interests}

The authors declare that they have no competing interests.

\section{Authors' contributions}

YJK, MYL and HKS participated in the design of the study data analyses and manuscript preparation. YJK, MYL, WYJ and YSK conducted the assays and analyses. All authors read and approved the final manuscript.

\section{Acknowledgments}

This research was part of a project (The Evidence Based Medicine for Herbal Formula) funded by the Basic Herbal Medicine Research Group in the Korean Institute of Oriental Medicine.

Received: 6 December 2013 Accepted: 24 September 2014

Published: 29 September 2014

\section{References}

1. Busse WW, Lemanske RF Jr: Asthma. N Eng J Med 2001, 344:350-362.

2. Holgate ST: Pathogenesis of asthma. Clin Exp allergy 2008, 38:872-897.

3. Mosmann TR, Moore KW: The role of IL-10 in cross regulation of TH1 and TH2 responses. Immunol Today 1991, 12:A49-A53.

4. Kirkham P, Rahman I: Oixative stress in asthma and COPD: antioxidants as a therapeutic strategy. Pharmacol Ther 2006, 111:476-494.

5. Richter C, Gogvadze V, Laffranchi R, Schlapbach R, Schweizer M, Suter M, Walter P, Yaffee M: Oxidants in mitochondria: from physiology to diseases. Biochim Biophys Acta 1995, 1271:67-74.

6. Ahmad A, Shameem M, Husain Q: Relation of oxidant-antioxidant imbalance with disease progression in patients with asthma. Ann Thorac Med 2012, 7:226-232.

7. Weon JB, Ma JY, Yang HJ, Ma CJ: Quantitative analysis of compounds in fermented insampaedok-san and their neuroprotective activity in HT22 cells. Nat Prod Sci 2011, 17:58-63.

8. Wang MT: A report of 52 cases of common cold with the treatment of renshenbaidusan (in Chinese). Yunnan J Tradit Chin Med Materia Medica 2002, 23:46-47.

9. Wei Q, Li XR, Kang Y, Liu X, Wang RM: Observation of ren shen bai du capsule for the treatment of 150 cases of cold caused by qi deficiency (in Chinese). J Shanxi Med College Continuing Edu 1996, 6:24-25.

10. Bai HT: Clinical observation of 50 cases of bronchial asthma using renshenbaidusan (in Chinese). Tianjin Pharmacy 2008, 20:54-55.

11. Zhang LX, Liu LC: Clinical analysis of 72 cases of cough variant asthma using renshenbaidusan (in Chinese). Shenzhen J Integr Tradit Chin West Med 2010, 20:39-40. 
12. Lim HS, Ha H, Seo CS, Jin SE, Kim YJ, Jeon WY, Yoo SR, Shin IS, Kim JH, Kim SS, Shin N, Lee MY, Jeong SJ, Kim OS, Shin HK: Comparative study on efficacies and ingredient contents of different solvent extracts of Insampaedok-san. Kor J Herbology 2012, 27:115-122.

13. Re R, Pellegrini N, Proteggente A, Pannala A, Yang M, Rice-evans C: Antioxidant activity applying an improved ABTS radical cation decolorization assay. Free Radical Biol Med 1999, 26:1231-7.

14. Moreno MI, Isla MI, Sampietro AR, Vattuone MA: Comparison of the free radical-scavenging activity of propolis from several regions of Argentina. J Ethnophamacol 2000, 71:109-14.

15. Leung PC: A practical way of research in Chinese medicine. Ann Acad Med Singapore 2006, 35:770-772.

16. Bent S: Herbal medicine in the United States: review of efficacy, safety, and regulation. J Gen Intern Med 2008, 23:854-859.

17. Cho YS, Moon HB: The role of oxidative stress in the pathogenesis of asthma. Allergy Asthma Immunol Res 2010, 2:183-187.

18. Bowler RP: Oxidative stress in the pathogenesis of asthma. Curr Allergy Asthma Rep 2004, 4:116-122.

19. Kang KS, Kim HY, Pyo JS, Yokozawa T: Increase in the free radical scavenging activity of ginseng by heat-processing. Biol Pharm Bull 2006, 29:750-754.

20. Shin MS, Han HS, Lee YJ: Comparative studies on the anti-oxidation activities of Aralia continentalis root and Angelica pubescens root. Kor J Herbology 2009, 24:67-76

21. Kim YD, Mahinda S, Koh KS, Jeon YJ, Kim SH: Reactive oxygen species scavenging activity of Jeju native Citrus peel during maturation. J Korean Soc Food Sci Nutr 2009, 38:462-469.

22. Choi $C Y$, Lee $K J$, Jeong HG: Effects of aqueous extract isolated from Platycodon grandiflorum against t-Buty lhydroperoxide-induced oxidative stress in rat primary hepatocytes. J Pharmaceut Soc Korea 2002, 46:466-471.

23. Lee $\mathrm{JH}$, Choi HS, Chung MS, Lee MS: Volatile flavour components and free radical scavenging activity of Cnidium Officinale. Korean J Food SC Technol 2002, 34:330-338.

24. Ahmed AS, McGaw LJ, Eloff JN: Evaluation of pharmacological activities, cytotoxicity and phenolic composition of four Maytenus species used southern African traditional medicine to treat intestinal infections and diarrhoeal diseases. BMC Complement Altern Med 2013, 13:100.

25. Shanmugasundaram KR, Kumar SS, Rajajee S: Excessive free radical generation in the blood of children suffering from asthma. Clin Chim Acta 2001, 305:107-114.

26. Saetta M, Turato G: Airway pathology in asthma. Eur Respir J 2001, 18:18s-23s.

27. Carroll N, Cooke C, James A: The distribution of eosinophils and lymphocytes in the large and small airways of asthmatics. Eur Respir $J$ 1997, 10:292-300.

28. Saeed W, Badar A, Hussain MM, Aslam M: Eosinophils and eosinophil products in asthma. J Ayub Med Coll Abbottabad 2002, 14:49-55.

29. Deo SS, Mistry KJ, Kakade AM, Niphadkar PV: Role played by Th2 type cytokines in lgE mediated allergy and asthma. Lung India 2010, 27:66-71.

30. Stanciu LA, Djukanovic R: The role of ICAM-1 on T-cells in the pathogenesis of asthma. Eur Respir J 1998, 11:949-957.

31. Greenfeder S, Umland SP, Cuss FM, Chapman RW, Egan RW: Th2 cytokines and asthma - The role of interleukin-5 in allergic eosinophilic disease. Respir Res 2001, 2:71-79.

32. Truyen E, Coteur L, Dilissen E, Overbergh L, Dupont LJ, Ceuppens JL, Bullens DMA: Evaluation of airway inflammation by quantitative Th1/Th2 cytokine mRNA measurement in sputum of asthma patients. Thorax 2006, 61:202-208.

33. Conroy DM, Williams TJ: Eotaxin and the attraction of eosinophils to the asthmatic lung. Respir Res 2001, 2:150-156.

34. Shale DJ, Lonescu AA: Mucus hypersecretion: a common symptom, a common mechanism? Eur Respir J 2004, 23:797-798.

35. Galli SJ, Tsai M: IgE and mast cells in allergic disease. Nat Med 2012, 18:693-704

36. Oettgen HC, Geha RS: IgE regulation and roles in asthma pathogenesis. J Allergy Clin Immunol 2001, 107:429-440.

37. Haile S, Lefort J, Joseph D, Gounon P, Huerre M, Vargaftig BB: Mucous-cell metaplasia and inflammatory-cell recruitment are dissociated in allergic mice after antibody- and drug-dependent cell depletion in a murine model of asthma. Am J Respir Cell Mol Biol 1999, 20:891-902.
38. Dabbagh K, Takeyama K, Lee HM, Ueki IF, Lausier JA, Nadel JA: IL-4 induces mucin gene expression and globlet cell metaplasia in vitro and in vivo. J Immunol 1999, 162:6233-6237.

39. Dworski R: Oxidant stress in asthma. Thorax 2000, 55:S51-S53.

40. Adcock IM, Brown CR, Kwon O, Barnes PJ: Oxidative stress induces NF kappa B DNA binding and inducible NOS mRNA in human epithelial cells. Biochem Biophys Res Commun 1994, 199:1518-1524.

41. Comhair SA, XuW GS, Thunnissen FB, Almasan A, Calhoun WJ, Janocha AJ, Zheng L, Hazen SL, Erzurum SC: Superoxide dismutase inactivation in pathophysiology of asthmatic airway remodeling and reactivity. Am J Pathol 2005, 166:663-674.

doi:10.1186/1472-6882-14-365

Cite this article as: Kim et al:: Acute oral toxicity of Insampaedok-san, a traditional herbal formula, in rats and its protective effects against ovalbumin-induced asthma via anti-inflammatory and antioxidant properties. BMC Complementary and Alternative Medicine 2014 14:365.

\section{Submit your next manuscript to BioMed Central and take full advantage of:}

- Convenient online submission

- Thorough peer review

- No space constraints or color figure charges

- Immediate publication on acceptance

- Inclusion in PubMed, CAS, Scopus and Google Scholar

- Research which is freely available for redistribution 